\title{
Monitoring of surface deformation in open pit mine using DInSAR time- series: a case study in the N5W iron mine (Carajás, Brazil) using TerraSAR-X data
}

José C. Mura, Waldir R. Paradella, Fabio F. Gama, Athos R. Santos, Mauricio Galo, et al.

José C. Mura, Waldir R. Paradella, Fabio F. Gama, Athos R. Santos, Mauricio Galo, Paulo O. Camargo, Arnaldo Q. Silva, Guilherme G. Silva, "Monitoring of surface deformation in open pit mine using DInSAR time-series: a case study in the N5W iron mine (Carajás, Brazil) using TerraSAR-X data," Proc. SPIE 9243, SAR Image Analysis, Modeling, and Techniques XIV, 924311 (21 October 2014); doi: 10.1117/12.2066886 


\title{
Monitoring of Surface Deformation in Open Pit Mine Using DInSAR Time-Series: A Case Study in the N5W Iron Mine (Carajás, Brazil) using TerraSAR-X data
}

\author{
José C. Mura a, Waldir R. Paradella a, Fabio F. Gama a, Athos R. Santos a, \\ Mauricio Galo ${ }^{\mathrm{b}}$, Paulo O. Camargo ${ }^{\mathrm{b}}$, Arnaldo Q. Silva ${ }^{\mathrm{c}}$, Guilherme G. Silva ${ }^{\mathrm{a}}$ \\ ${ }^{a}$ National Institute for Space Research (INPE), São José dos Campos, Brazil \\ ${ }^{\mathrm{b}}$ São Paulo State University (FCT/UNESP), Presidente Prudente, Brazil \\ ${ }^{\mathrm{c}}$ Federal University of Pará (IG/UFPA), Belém, Brazil
}

\begin{abstract}
We present an investigation of surface deformation using Differential SAR Interferometry (DInSAR) time-series carried out in an active open pit iron mine, the N5W, located in the Carajás Mineral Province (Brazilian Amazon region), using 33 TerraSAR-X (TSX-1) scenes. This mine has presented a historical of instability and surface monitoring measurements over sectors of the mine (pit walls) have been done based on ground based radar. Two complementary approaches were used: the standard DInSAR configuration, as an early warning of the slope instability conditions, and the DInSAR timeseries analysis. In order to decrease the topographic phase error a high resolution DEM was generated based on a stereo GeoEye-1 pair. Despite the fact that a DinSAR contains atmospheric and topographic phase artifacts and noise, it was possible to detect deformation in some interferometric pairs, covering pit benches, road ramps and waste piles. The timeseries analysis was performed using the 31 interferometric pairs, which were selected based on the highest mean coherence of a stack of 107 interferograms, presenting less phase unwrapping errors. The time-series deformation was retrieved by the Least-Squares (LS) solution using an extension of the Singular Value Decomposition (SVD), with a set of additional weighted constrain on the acceleration deformation. The atmospheric phase artifacts were filtered in the space-time domain and the DEM height errors were estimated based on the normal baseline diversity. The DInSAR time-series investigation showed good results for monitoring surface displacement in the N5W mine located in a tropical rainforest environment, providing very useful information about the ground movement for alarm, planning and risk assessment.
\end{abstract}

Keywords: DInSAR time-series, surface deformation, TerraSAR-X, open pit iron mine, Amazon Region

\section{INTRODUCTION}

Instabilities can be expected at any mining activity; open pit operations usually have significant areas of extent and can also influence large portions of terrain adjacent to the pit crest. Rock mass movements and surface deformations potentially lead to slope instabilities or wall failures due to regular open pit mining operations. This scenario in Carajás gets worse over time due to intense deep excavations in saprolitic soil and rock masses of very low geomechanical quality, coupled with blasting practices and heavy precipitation of the moist tropics, with deleterious effects on the overall stability.

The use of standard Differential SAR Interferometry (DInSAR) technique for monitoring surface deformation has been applied since the early 90s. ${ }^{1-7}$ Multi-temporal acquisitions improve the capability to detect the temporal change of the deformation phenomena. To take advantage of it DInSAR time-series have been proposed and used successfully. ${ }^{8-13}$ This technique using a small baseline (SBAS) subset $^{14}$ has been applied by several authors. ${ }^{15-18}$ Persistent Scatterer Interferometry (PSI) approach ${ }^{19-22}$ based on a stack of differential interferograms, relies on identifying pixels whose scattering properties vary little with time and look angle, allowing a temporal analysis of the interferometric phase of individual point targets, and providing an accurate information related to the surface target displacements. PSI provides better accuracy than that of DInSAR time-series technique. The former can better model and diminish the effect of the atmospheric phase, which is related to the path delay heterogeneity during the acquisitions times, whereas the latter can 
detect larger deformation rates and provides a more homogeneous and extensive information related to the ground deformation, but at the cost of a loss in spatial resolution.

This study presents an application of DInSAR to monitor surface deformation in an open pit iron mine, the N5W, located in Carajás Mineral Province (Brazilian Amazon region). In the next section a description of this particular mine as well as some related ground deformation instabilities are presented. The standard DInSAR and time-series approaches using 33 StripMap TSX-1 scenes are presented in the section 3. The results obtained from the interferometric measurements using the two DInSAR approaches and quantitative field measurements from a ground based radar are presented in section 4. Finally, the potential and the results of the DInSAR technique are discussed for an operational monitoring aiming at mining planning and risk assessments.

\section{STUDY AREA}

Carajás Province, located on the easternmost border of the Amazon Region, is the most important Brazilian mineral province and encompasses the world's largest iron deposits. The Province, with an area of $120,000 \mathrm{Km}^{2}$, is marked by mountainous terrains, characterized by a set of hills and plateaus (altitudes from 500 to $900 \mathrm{~m}$ ) surrounded by southern and northern lowlands (altitudes around $200 \mathrm{~m}$ ), deep chemical weathering which produces thick oxisols (latosols), totally covered by Ombrophilous Equatorial forest communities with complex and multilevel canopies and numerous species. $^{23}$

The iron deposits are covered by thick, hard iron-crust (lateritic duricrusts) developed over volcanic rocks and ironstones. Specific low-density savanna-type vegetation (campus rupestres) is associated with the deposits, and shows a strong contrast (clearing) with the dense equatorial forest. Fully owned by Vale S.A. mining company, the exploration in Carajás is carried out through state of the art open pit benching. The current mining activities are related to two iron orebodies (N4 and N5) and were started by 1984 with the N4E mine and the N5W mine in 1998. Carajás Mining Complex (N4 and N5 bodies) produces approximately 300,000 metric tons of iron ore per day. ${ }^{24}$

Surface instabilities have been detected by visual inspection carried out by Vale's geotechnical team in the N5W mine (Figure 1) through the presence of fractures on bench walls, tension cracks on berms and road ramps. In addition, a field monitoring program based on the ground based Slope Stability Radar (Figure 2) and total station/reflecting prisms (Figure 3) has provided quantitative surface displacement information since March 20, 2012. ${ }^{25}$ The onset of instabilities remained without significant evolution up August12, 2012, when there was a reactivation with relevant displacement on bench faces and berms.

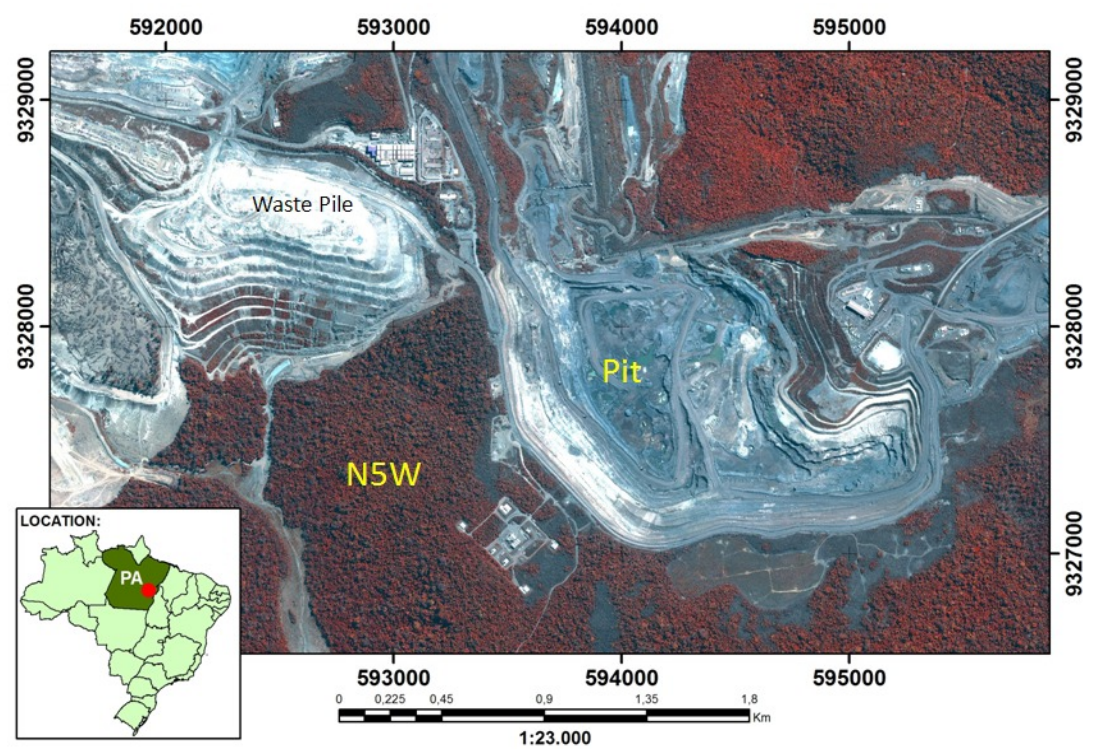

Figure 1. Study area (N5W iron ore mine: Carajás-Brazilian Amazon) 


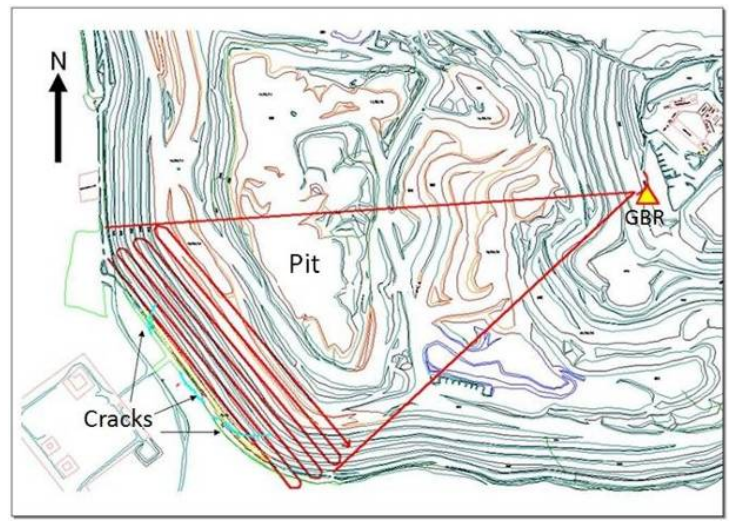

Figure 2. Monitoring of the N5W pit walls with ground based radar (source: Vale S.A.)

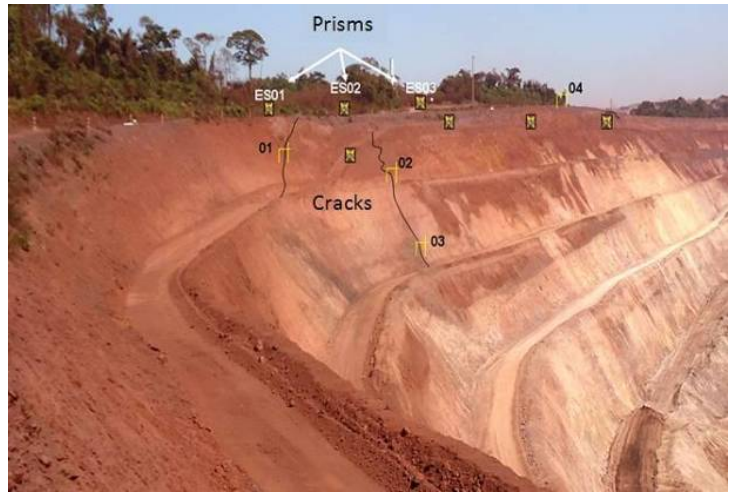

Figure 3. N5W pit wall showing some cracks being monitored by ground based radar and total station/reflective prisms (source: Vale S.A)

\section{METHODOLOGY}

\subsection{DInSAR technique}

Standard DInSAR aims to measure deformation on the ground using a pair of SAR images acquired at different times and different position of the satellite between the two acquisitions. The interferogram generated from these two coregistrated images has phase's components contributions from the topography, deformations, atmosphere and noise. By knowing the positions of the satellite and the surface topography it is possible to subtract the topographic phase component and to measure the deformation. Performing this previous proceeding what remains in the differential interferogram is a contribution due to the ground displacement between acquisitions added with other undesirable component, represented by:

$$
\phi_{\Delta t}=\phi_{d e f}+\phi_{h}+\phi_{a t m}+\phi_{\beta}+\phi_{\eta}
$$

where $\phi d e f$ is the phase change due to the displacement of the pixel in the satellite line-of-sight (LoS) direction, $\phi_{h}$ is the topographic phase error, $\phi_{a t m}$ is the atmospheric phase delay, $\phi_{\beta}$ is the residual phase due to orbit errors and $\phi_{\eta}$ is the phase noise. The ambiguity of $2 \pi$ in the differential interferometric phase (fringes) makes it impossible to interpret this phase in terms of absolute range change. However, it is possible to estimate the relative range change between points within a differential interferogram, by integrating the number of fringes between them, using a process known as phase unwrapping. 
The use of standard DInSAR technique for ground deformation monitoring is suitable when the $\phi$ def exceeds the other four phase components represented in the equation (1), for this reason the use of a precise DEM is desirable to compensate part of the topographic phase error; a spatial filtering (multi-look) can reduce the phase noise, however the atmospheric phase delay and the residual phase due to orbit errors cannot be filtered out or estimated, respectively. Despite the drawbacks this technique has been applied yet.

In this study, this technique was applied in order to have an early warning of the slope instability conditions covering pit benches of the $\mathrm{N} 5 \mathrm{~W}$ mine. Is was generated 32 differential interferometric pairs covering the time span from March 2012 to April 2013 (dry and wet seasons) using 33 StripMap TerraSAR-X images; the results are shown in the next section. Due to complex topography of the mine area (deep excavations, high waste piles, etc.), a high resolution DEM was generated based on a stereo GeoEye-1 pair $^{26}$ in order to decrease the topography phase error in the DInSAR analysis.

\subsection{DInSAR time-series}

Algorithms for DInSAR time-series analysis have been developed do better address the standard DInSAR limitations, by using a redundant number of differential interferograms with potential to determine spatially and temporally ground displacement, where the desirable deformation information can be separated from topography error, atmospheric delay and noise. ${ }^{27}$

Let us consider a set of $\mathrm{M}$ differential interferograms based on a set of $\mathrm{N}+1 \mathrm{SAR}$ images acquired at the ordered time ( $\mathrm{t}_{0}$, $\left.\mathrm{t}_{1}, \ldots, \mathrm{t}_{\mathrm{N}}\right)$, where each differential interferometric pair is constructed in a given time interval $(\Delta \mathrm{t})$, as represented in equation (1), following the rule of small time interval between acquisitions or small baseline subset (SBAS). ${ }^{14}$ Considering a reference point located in a stable area and a selected generic point, the observed unwrapped phase values of this point in relation to the reference point may be organized in a vector of $M$ elements.

$$
\phi_{O b}^{T}=\left[\phi_{\Delta t 1}, \phi_{\Delta t 2}, \ldots, \phi_{\Delta t M}\right]
$$

Let $\mathrm{N}$ be the number of unknown phase values related to the range displacement of the selected point at the ordered time $\left(\mathrm{t}_{1}, \mathrm{t}_{2}, \ldots, \mathrm{t}_{\mathrm{N}}\right)$, considering $\mathrm{t}_{0}$ as a reference epoch (zero deformation), represented in a vector form:

$$
\phi_{\text {disp }}^{T}=\left[\phi_{\Delta r 1}\left(t_{1}\right), \phi_{\Delta r 2}\left(t_{2}\right), \ldots, \phi_{\Delta r N}\left(t_{N}\right)\right]
$$

The relation between range displacement (3) and the observed data (2) can be represented as one system of $\mathrm{M}$ equation and $\mathrm{N}$ unknown variables in the following matrix form:

$$
A \phi_{\text {disp }}=\phi_{O b}
$$

where $\mathrm{A}$ is a $\mathrm{M}$ by $\mathrm{N}$ matrix of the operators $(+1,-1,0)$ between the unwrapped interferometric pairs.

The solution of equation (4) can be obtained in sense of Least Squares (LS) ${ }^{9}$, by

$$
\phi_{\text {disp }}=A^{+} \phi_{\mathrm{Ob}}
$$

where $\mathrm{A}^{+}=\left(\mathrm{A}^{\mathrm{T}} \mathrm{A}\right)^{-1} \mathrm{~A}^{\mathrm{T}}$ is the pseudoinverse of $\mathrm{A}$.

In the case of having a large number of differential interferometric pairs to increase the temporal sampling, the rank of $\mathrm{A}$ will be less them $\mathrm{N}$ and therefore the system will have infinite solutions. To overcome this drawback the system in (4) can be inverted by applying the SVD method ${ }^{28}$. The solution of (5) may present some discontinuities in the cumulative displacement in range, which is a generally non physically sound solution, a more effective solution is obtained by minimizing the velocity norm. ${ }^{14}$

In this study, the time-series deformation was retrieved by using an extension of the SVD with a set of additional weighted constrain on the acceleration of the displacement to control the smoothness of the time-series solutions. ${ }^{10}$ Temporal smoothing is enhanced using a finite difference approximation constraint, assuming less deformation to occur during short period of time. Thus by including a smoothing constraint, atmospheric artifacts will be minimized depending on how strongly temporal smoothing is applied. The smoothing constraint and the height error related term were incorporated into the inversion of the system, that relates the observed unwrapped interferograms phase $\left(\phi_{O b}\right)$ with the average displacement velocity $(\mathrm{Vd})$, as follow: ${ }^{29}$ 


$$
\left[\begin{array}{cc}
G & \phi_{\partial h} \\
\Gamma & 0
\end{array}\right]\left[\begin{array}{l}
V_{d} \\
h_{e}
\end{array}\right]=\left[\begin{array}{l}
\phi_{O b} \\
0
\end{array}\right]
$$

where G represents a M by N matrix defining the configuration of the time intervals between interferometric pairs, $\phi_{\partial \mathrm{h}}$ is a $\mathrm{M}$ vector defining the derivative of $\phi_{O b}$ in relation to the height for the topographic error estimation (he), $\mathrm{Vd}$ is a $\mathrm{N}$ vector representing the average displacement velocity of each epoch and $\Gamma$ is a (M-3) by $N$ matrix containing the constrain values on the displacement acceleration, represented by:

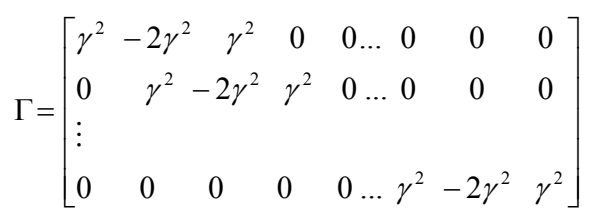

where $\gamma$ is the smoothing factor, varying from no smoothing $(\gamma=0)$ to a solutions that are essentially linear (large $\gamma$ ).

The time-series solution used in this study was based on (6), which was implemented in the SAR and Interferometric package by GAMMA Remote Sensing and Consulting AG (GAMMA). The phase model also includes a height related term proportional to the derivative of the interferometric phase with respect to height, which depends on the normal baseline diversity. This additional degree of freedom allows calculation of a height correction for all the interferograms that minimizes the phase residuals in a LS sense. If the value of the smoothing parameter $\gamma$ is set to 0 , then the value of the height correction will be very close to 0.0 since the phase can then be fully attributed to range displacement or atmosphere. Only when $\gamma>0$ the height corrections can be calculated and the network of measurements should not have phase unwrapping errors when estimating the height corrections. Larger values of gamma ( $\gamma>1$ up to 10), will result in better height estimates especially when the deformation is essentially linear.

The application of the DInSAR time-series in this study using the 33 TerraSAR-X images was firstly based on a test of coherence of the interferograms in the N5W mine's area, according to the time interval between interferometric pair. This test was carried out in order to select the maximum time interval for construction of the pairs. This procedure was taken due to the environment characteristic of the study area, which is an active iron mine surrounded by a tropical forest subject to rain, dust, intense surface changes due to ongoing mining operation; all of them affecting and contributing to a temporal decorrelation. All interferograms were obtained by using a complex multi-look operation, with 2 looks in range and azimuth, resulting in a pixel dimension of about 2.6 and $3.8 \mathrm{~m}$ in range and azimuth, respectively. Adaptive spectral filter with window size equal to 32 by 32 was applied on the interferograms to produce interferometric coherence images. ${ }^{30}$ Regions with coherence less than 0.3 have been masked out. The phase unwrapping process of the interferograms was carried out by using the algorithm $\mathrm{MCF}^{31}$

Figure 4 shows the box plot of the mean coherence and standard deviation of the DInSAR pairs according to the time interval used, limited to 88 days and perpendicular baseline up to $800 \mathrm{~m}$. From Figure 4 we notice that the highest values of the coherence were found for the shortest time interval independent of the baseline size, which is 11 days for TerraSAR-X data.

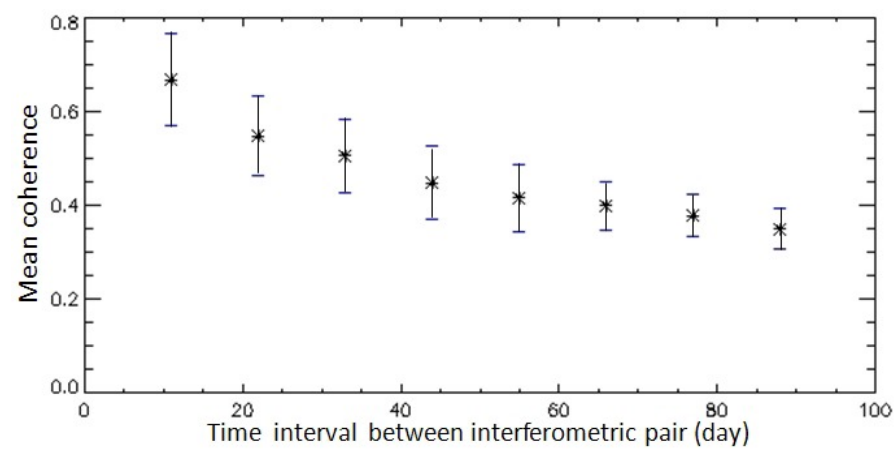

Figure 4. Mean coherence versus time interval of the interferometric pair 
The SAR images acquisitions were carried out from March 20, 2012 to April 20, 2013. It was planned do have one image ever 11 days but this sequence failed twice, creating discontinuities of 22 and 44 days. In order to cover the time span of acquisitions it was simulate the differential interferometric pairs for a time interval up to 45 days and a maximum perpendicular baseline up to $800 \mathrm{~m}$. A total of 107 pairs where found and for each one it was computed its mean coherence, the time interval and the perpendicular baseline, as shown in the Table 1.

We can notice from Table 1 that the highest coherence of the interferometric pairs (gray color) was found for a time interval equal to 11-day, independent of the baseline value, with some exceptions in the pairs 10,16 and 35 due to discrepancies in the baseline values. The pairs 96 and 102 presented failures in the sequence of acquisitions.

Table 1. Differential Interferometric Pairs for Bp up to $800 \mathrm{~m}$ and Bt up to 45 days

\begin{tabular}{|c|c|c|c|c|c|c|c|c|c|c|c|c|c|}
\hline Pair & Master & Slave & Bp & Bt & Coh & Se & Pair & Master & Slave & Bp & Bt & Coh & Se \\
\hline 1 & \multirow{4}{*}{20120320} & 20120331 & -156 & 11 & 0.56 & \multirow{16}{*}{ 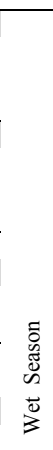 } & 55 & \multirow{4}{*}{20120821} & 20120901 & 41 & 11 & 0.85 & \multirow{24}{*}{$\begin{array}{l}\tilde{0} \\
\tilde{\Xi} \\
\tilde{\omega} \\
\vec{D}\end{array}$} \\
\hline 2 & & 20120411 & -214 & 22 & 0.47 & & 56 & & 20120912 & -32 & 22 & 0.77 & \\
\hline 3 & & 20120422 & 331 & 33 & 0.40 & & 57 & & 20120923 & 426 & 33 & 0.58 & \\
\hline 4 & & 20120503 & -192 & 44 & 0.41 & & 58 & & 20121004 & 284 & 44 & 0.50 & \\
\hline 5 & \multirow{4}{*}{20120331} & 20120411 & -57 & 11 & 0.72 & & 59 & \multirow{4}{*}{20120901} & 20120912 & -74 & 11 & 0.85 & \\
\hline 6 & & 20120422 & 487 & 22 & 0.49 & & 60 & & 20120923 & 384 & 22 & 0.67 & \\
\hline 7 & & 20120503 & -35 & 33 & 0.52 & & 61 & & 20121004 & 242 & 33 & 0.55 & \\
\hline 8 & & 20120514 & 180 & 44 & 0.45 & & 62 & & 20121015 & 436 & 44 & 0.37 & \\
\hline 9 & \multirow{4}{*}{20120411} & 20120422 & 545 & 11 & 0.57 & & 63 & \multirow{4}{*}{20120912} & 20120923 & 458 & 11 & 0.72 & \\
\hline 10 & & 20120503 & 21 & 22 & 0.58 & & 64 & & 20121004 & 317 & 22 & 0.58 & \\
\hline 11 & & 20120514 & 237 & 33 & 0.47 & & 65 & & 20121015 & 510 & 33 & 0.37 & \\
\hline 12 & & 20120525 & 521 & 44 & 0.38 & & 66 & & 20121026 & 500 & 44 & 0.38 & \\
\hline 13 & \multirow{4}{*}{20120422} & 20120503 & -523 & 11 & 0.49 & & 67 & \multirow{4}{*}{20120923} & 20121004 & -141 & 11 & 0.70 & \\
\hline 14 & & 20120514 & -307 & 22 & 0.50 & & 68 & & 20121015 & 51 & 22 & 0.50 & \\
\hline 16 & & 20120525 & -23 & 33 & 0.55 & & 69 & & 20121026 & 41 & 33 & 0.50 & \\
\hline 17 & & 20120605 & -413 & 44 & 0.40 & & 70 & & 20121106 & -506 & 44 & 0.37 & \\
\hline 18 & \multirow{4}{*}{20120503} & 20120514 & 215 & 11 & 0.65 & & 71 & \multirow{4}{*}{20121004} & 20121015 & 193 & 11 & 0.64 & \\
\hline 19 & & 20120525 & 499 & 22 & 0.49 & & 72 & & 20121026 & 182 & 22 & 0.53 & \\
\hline 20 & & 20120605 & 110 & 33 & 0.55 & & 73 & & 20121106 & -365 & 33 & 0.44 & \\
\hline 21 & & 20120616 & -108 & 44 & 0.49 & & 74 & & 20121117 & 52 & 44 & 0.45 & \\
\hline 22 & \multirow{4}{*}{20120514} & 20120525 & 284 & 11 & 0.67 & & 75 & \multirow{4}{*}{20121015} & 20121026 & -10 & 11 & 0.78 & \\
\hline 23 & & 20120605 & -105 & 22 & 0.63 & & 76 & & 20121106 & -558 & 22 & 0.51 & \\
\hline 24 & & 20120616 & -324 & 33 & 0.50 & & 77 & & 20121117 & -140 & 33 & 0.54 & \\
\hline 25 & & 20120627 & 382 & 44 & 0.46 & & 78 & & 20121128 & -255 & 44 & 0.44 & \\
\hline 26 & \multirow{4}{*}{20120525} & 20120605 & -389 & 11 & 0.66 & & 79 & & 20121106 & -547 & 11 & 0.65 & \\
\hline 27 & & 20120616 & -608 & 22 & 0.50 & & 80 & 20121026 & 20121117 & -129 & 22 & 0.55 & \\
\hline 28 & & 20120627 & 98 & 33 & 0.58 & & 81 & 20121026 & 20121128 & -244 & 32 & 0.43 & \\
\hline 29 & & 20120708 & -382 & 44 & 0.44 & & 82 & & 20121209 & -296 & 44 & 0.36 & \\
\hline 30 & & 20120616 & -218 & 11 & 0.67 & & 83 & & 20121117 & 418 & 11 & 0.59 & \\
\hline 31 & & 20120627 & 487 & 22 & 0.51 & & 84 & & 20121128 & 302 & 22 & 0.43 & \\
\hline 32 & 20120605 & 20120708 & 7 & 33 & 0.57 & & 85 & 20121106 & 20121209 & 251 & 33 & 0.37 & \\
\hline 33 & & 20120719 & -154 & 44 & 0.48 & & 86 & & 20121220 & 421 & 44 & 0.33 & \\
\hline 34 & & 20120627 & 706 & 11 & 0.62 & & 87 & & 20121128 & -115 & 11 & 0.66 & \\
\hline 35 & & 20120708 & 226 & 22 & 0.64 & & 88 & & 20121209 & -167 & 22 & 0.44 & \\
\hline 36 & 20120616 & 20120719 & 64 & 33 & 0.59 & & 89 & 20121117 & 20121220 & 2 & 33 & 0.44 & \\
\hline 37 & & 20120708 & -480 & 11 & 0.68 & & 90 & & 20121209 & -51 & 11 & 0.57 & \\
\hline 38 & 20120627 & 20120719 & -641 & 22 & 0.49 & & 91 & 20121128 & 20121220 & 118 & 22 & 0.44 & \\
\hline 39 & & 20120730 & -204 & 33 & 0.52 & & 92 & 20121128 & 20130111 & -80 & 44 & 0.39 & D. \\
\hline 40 & & 20120719 & -161 & 11 & 0.71 & & 93 & & 20121220 & 170 & 11 & 0.66 & $\stackrel{\Xi}{\varpi}$ \\
\hline 41 & 20120708 & 20120730 & 275 & 22 & 0.58 & & 94 & 20121209 & 20130111 & -29 & 33 & 0.46 & 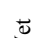 \\
\hline 42 & 20120708 & 20120810 & 389 & 33 & 0.50 & & 95 & 20121209 & 20130122 & -161 & 44 & 0.40 & 3 \\
\hline 43 & & 20120730 & 437 & 11 & 0.69 & & 96 & & 20130111 & -199 & 22 & 0.56 & \\
\hline 44 & & 20120810 & 551 & 22 & 0.57 & & 97 & & 20130122 & -331 & 33 & 0.38 & \\
\hline 45 & 20120719 & 20120821 & 41 & 33 & 0.65 & & 98 & 20121220 & 20130202 & -153 & 44 & 0.42 & \\
\hline 46 & & 20120901 & 83 & 44 & 0.60 & & 99 & & 20130122 & -131 & 11 & 0.70 & \\
\hline 47 & & 20120810 & $\begin{array}{l}0 J \\
114\end{array}$ & 11 & 0.84 & & 100 & 20130111 & 20130202 & 45 & 22 & 0.62 & \\
\hline 48 & & 20120821 & -395 & 22 & 0.65 & & 101 & 20130122 & 20130202 & 177 & 11 & 0.67 & \\
\hline 49 & 20120730 & 20120901 & -353 & 33 & 0.60 & & 102 & 20130202 & 20130318 & 1 & 44 & 0.47 & \\
\hline 50 & & 20120912 & -428 & 44 & 0.53 & & 103 & & 20130329 & 220 & 11 & 0.60 & \\
\hline 51 & & 20120821 & -509 & 11 & 0.72 & ర్ & 104 & 20130318 & 20130409 & 262 & 22 & 0.44 & \\
\hline 52 & 20120810 & 20120901 & -467 & 22 & 0.65 & లే & 105 & 20130318 & 20130420 & 122 & 33 & 0.44 & \\
\hline 53 & & 20120912 & -542 & 33 & 0.57 & $\overrightarrow{5}$ & 106 & & 20130409 & 42 & 11 & 0.61 & \\
\hline 54 & & 20120923 & -83 & 44 & 0.65 & & 107 & 20130329 & 20130420 & -97 & 22 & 0.50 & \\
\hline
\end{tabular}


The selection of the differential interferometric pairs was based on the criterion of the highest coherence, in order to reduce phase unwrapping errors. Based on that, the selected set of pairs is shown in Figure 5 in red color, covering the time span of the investigation. The green connections belong to those whose mean coherence values fell below those chosen. In Figure 5 the gray bars represent the time interval of 22 and 44 days due to the missing of acquisitions, respectively.

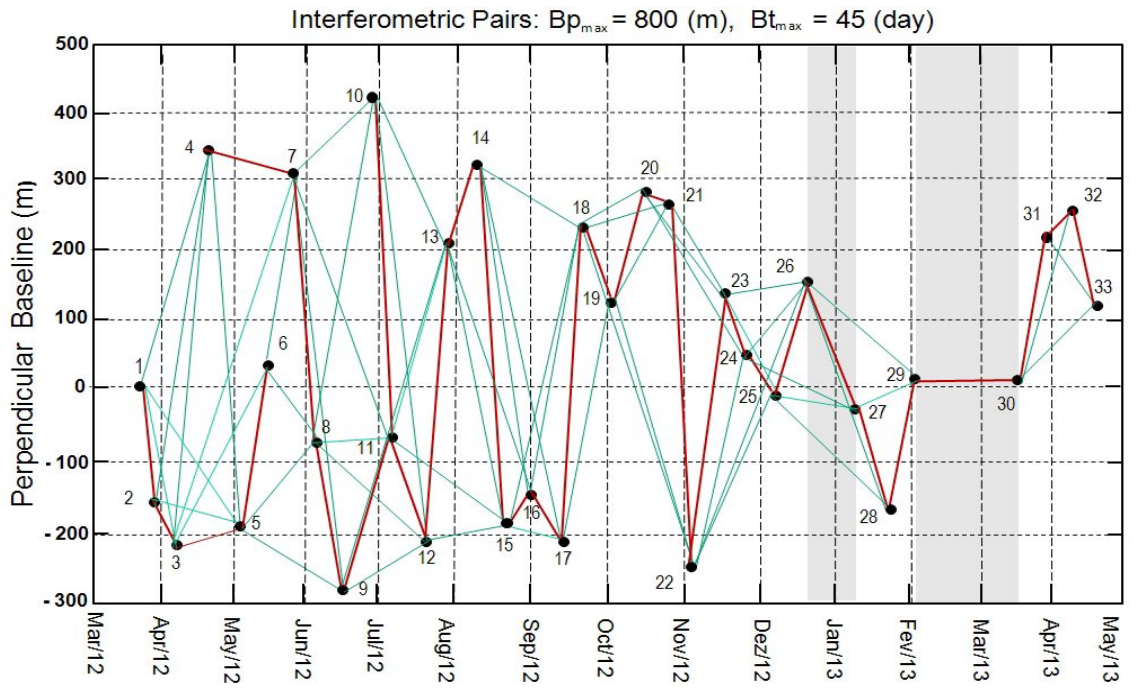

Figure 5. Interferometric pairs selected (red color) and discarded (green color)

The choice of the smoothing weight $(\gamma)$ is largely subjective. ${ }^{10}$ In this research, the selection of $\gamma$ was based on the standard deviation of the deformation measured on the position of the corner reflector located on a stable area. Figure 6 shows this measurement for $\gamma$ varying from 0 to 3.0, indicating that the standard deviation of the deformation stabilized for $\gamma>1.5$. Based on this analysis, it was used $\gamma=1.6$ for the DInSAR time-series solution.

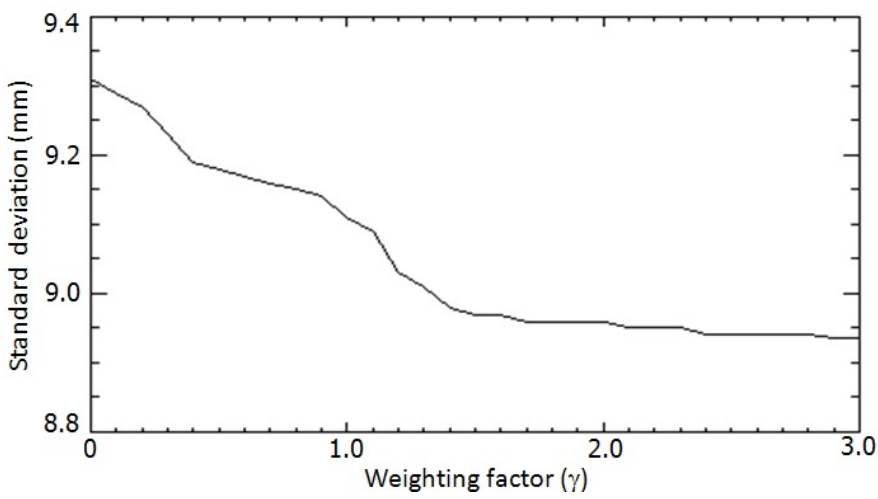

Figure 6. Standard deviation of the deformation of the time-series as a function of $\gamma$ measured on the corner reflector.

\section{RESULTS AND DISCUSSION}

The displacement maps were obtained from 32 standard DinSAR pairs, covering the time span from March 2012 to April 2013 (dry and wet seasons), using 33 TerraSAR-X images. From the 32 pairs available only 16 presented useful information, as shown in Figure 7, the remaining pairs were discarded due to the strong atmospheric phase influence. This effect can also be noticed in some sectors of the displacement images in Figure 7, represented in dark blue color. Despite the fact that DinSAR results still contain topographic error, atmospheric phase artifacts and noise, it was possible to detect the presence of deformation in many interferometric pairs, covering the pit benches and waste pile of the N5W 
mine, as shown in Figure 7 represented by the circles A and B, respectively. The use of the standard DInSAR configuration showed that this technique is very useful to get early information about slope instability conditions, due to the short period of SAR pair measurements.
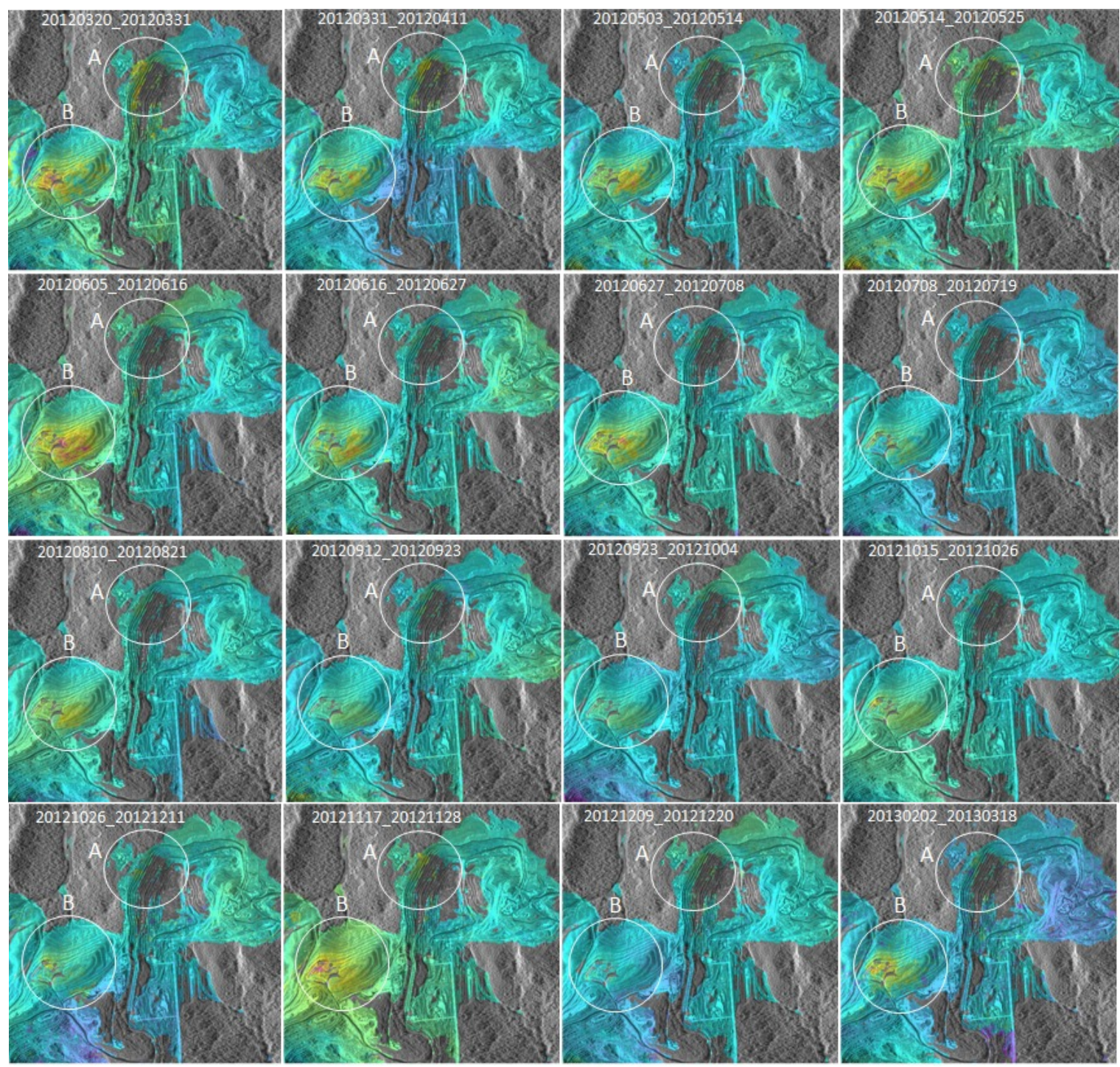

LOS displacement $(\mathrm{mm})$ $-40.0$

$-20.0 \quad 0.0$

Figure 7. DInSAR LoS displacement showing the circle A representing the pit slopes and B the waste pile

The results of the DInSAR time-series processing using the interferometric pairs configuration shown in Figure 5, brought richer information regarding the displacement velocity on the pit benches and on the waste pile, as shown in Figure 8 . The atmospheric phase artifacts were filtered out in the space-time domain and the DEM height errors were estimated based on the normal baseline diversity.

A highest deformation sector was detected over the waste pile with deformation rate equals to $-486.5 \mathrm{~mm} / \mathrm{year}$, as shown in the point $\mathrm{A}$ in Figure 8 and the graph in Figure 9a, which is normally expected for this manmade structure (indicative of settlements). High deformation was also detected along pit benches and ramps on the SW sector of the N5W mine, with deformation rate equals to $-255.7 \mathrm{~mm} /$ year, as shown in point B (Figure 8 and Figure $9 \mathrm{~b}$ ), which is associated with 
surface movement evidences (fractures on bench walls, tension cracks on berms and road ramps), and in situ quantitative measurements using SSR system. Two factors have contributed to this overall instability: deep excavation on low quality geomechanical ore/rock masses, and a structural control given by NW-SE trending shear zone and EW trending fault system, as mapped by BVP under a Vale's contract. ${ }^{32}$

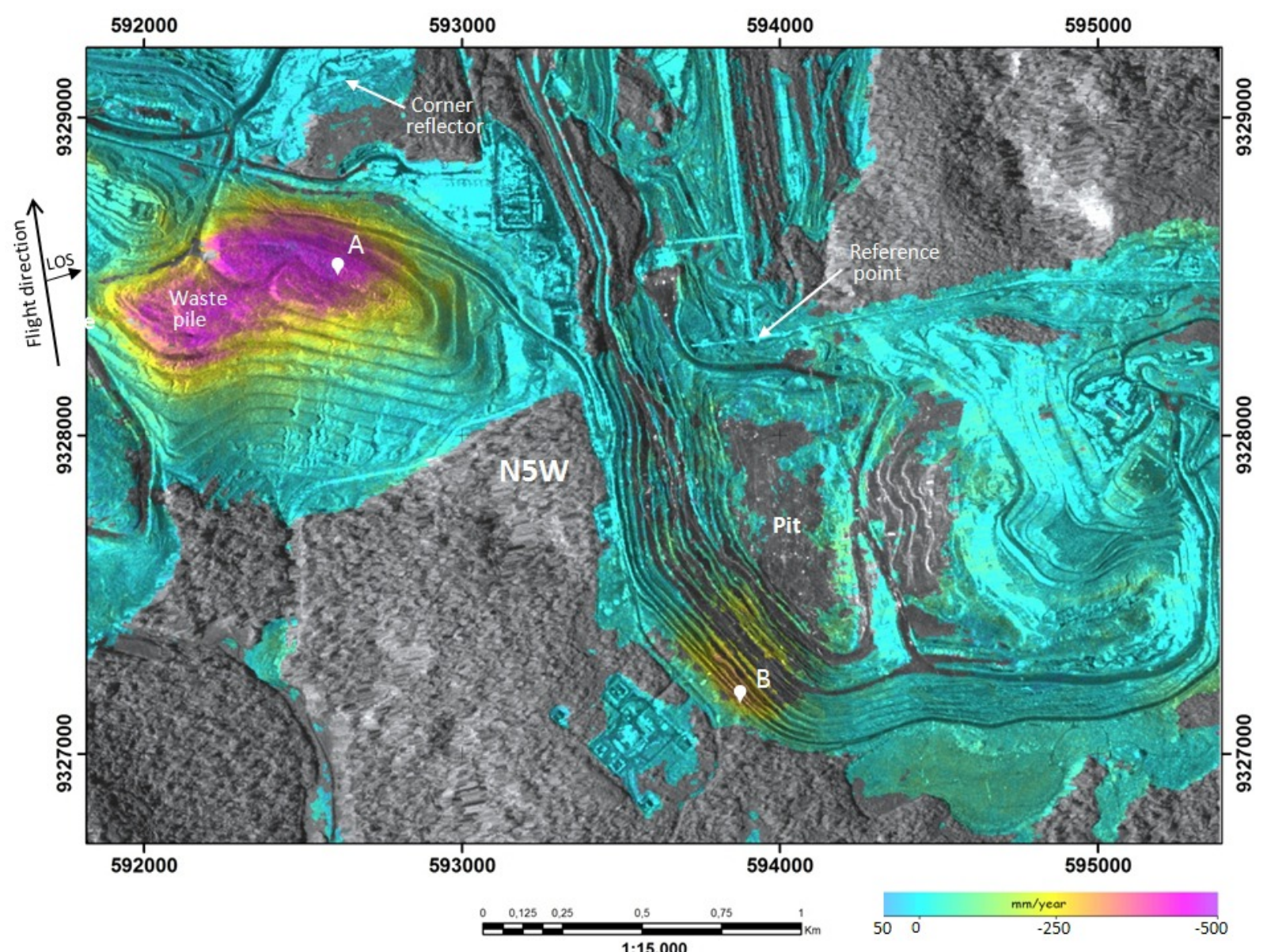

Figure 8 . Displacement velocity map of the N5W mining area in LoS direction

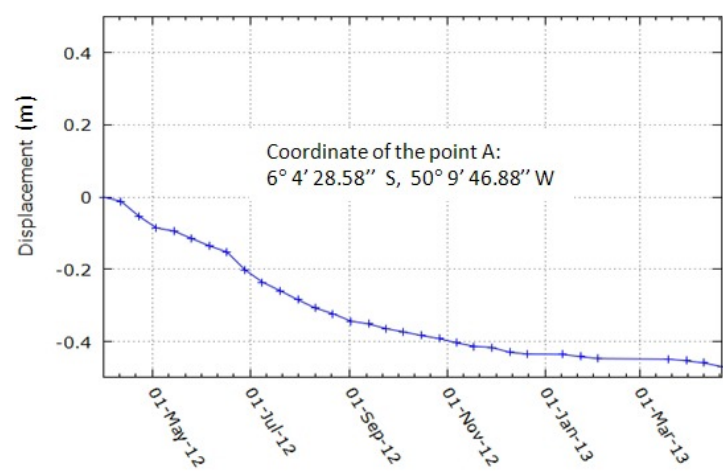

(a)

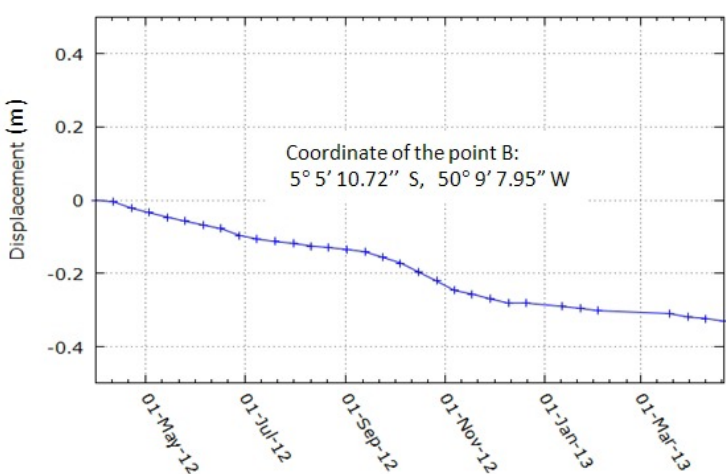

(b)

Figure 9 - Example of the accumulated deformation over a waste pile point $\mathrm{A}$ of the Figure 8 (a) and over a point located on cut slope B of the Figure 8 (b) 
Figure 10a shows the topographic height errors estimated through the normal baseline diversity configuration and Figure $10 \mathrm{~b}$ the standard deviation of the displacement velocity.

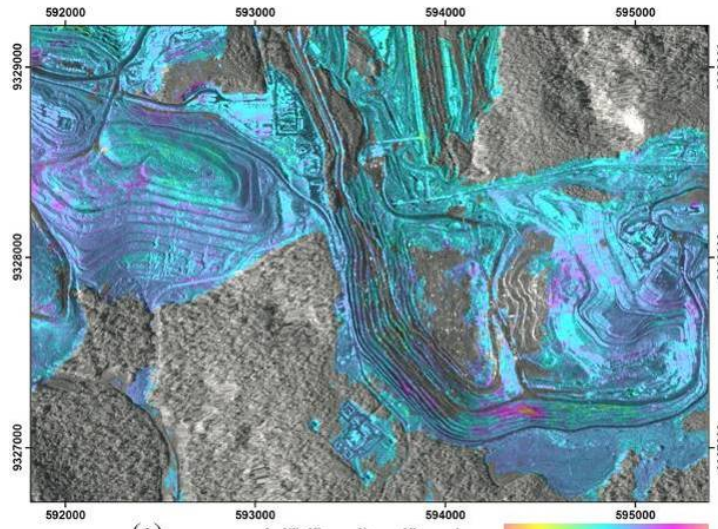

(a)

(a)

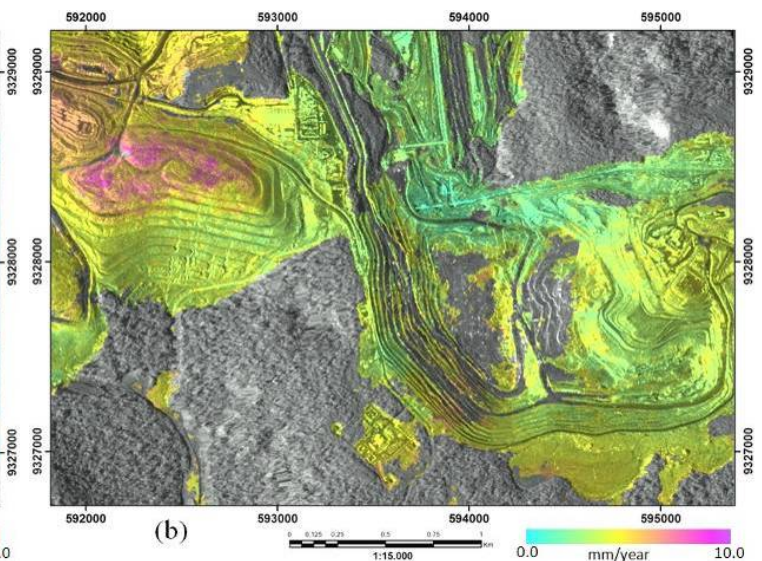

(b)

Figure 10. Estimated DEM error with $\gamma=1.6$ (a) and standard deviation of the deformation velocity (b)

In an attempt to validate the DInSAR time-series results with field surface displacements, slope stability radar (SSR) measurements, restricted to the monitoring of pit walls were used. Despite the short field monitoring period (17 up to 24 October, 2012), a small and continuous deformation pattern can be seen in Figure 11 for 9 points monitored on the pit wall, with a maximum accumulated LoS-projected SSR deformation value of $15 \mathrm{~mm}$. The jump in the graphics is due to adjust in the equipment.

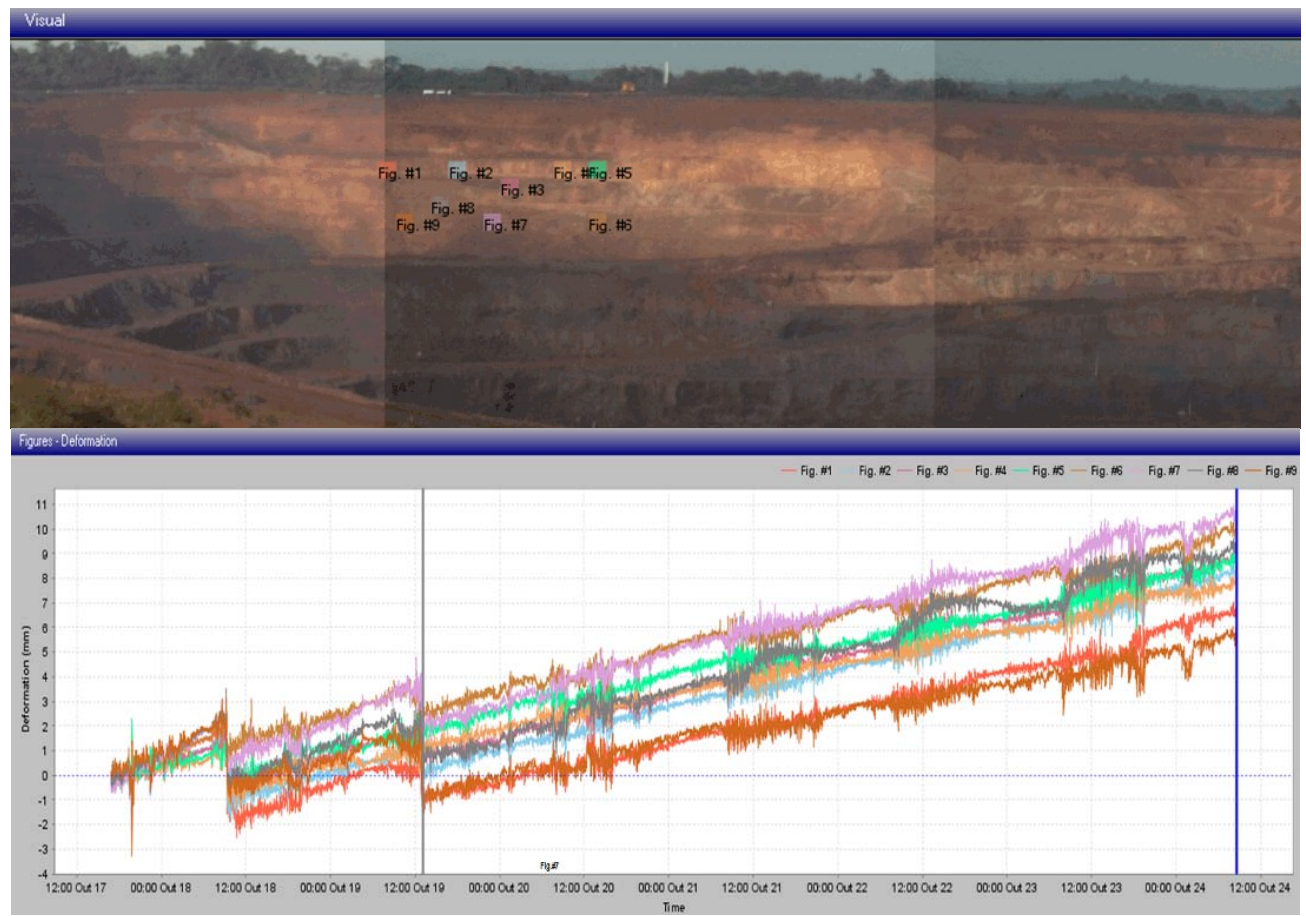

Figure 11. Monitoring using SSR in 9 points on the pit wall of the N5W (upper part of the figure shows the locations of the points and the lower part of the figure shows the graphics of the displacement in LOS-projected SSR geometry (source: Vale S.A). 
Considering that the measurements with satellite radar data (TSX-1) and ground based radar (SSR) have different lineof-sight (LoS) monitoring, it was difficult to compare both displacement information, but still can be noted that there was instability on the pit walls based on evidences shown by the two techniques. A complementary and accurate validation using total station/reflecting prisms measurement could be done, but unfortunately we have no access to these data.

\section{CONCLUSIONS}

Standard DInSAR approach showed useful ground displacement information in a short period of time, which is very clear on the waste pile and on the pit benches of the N5W mine. This early detection can be used for the exact location for the installation of ground geodetic surveys. DInSAR time-series analysis using 33 TSX-1 images covering the time span from March 2012 to April 2013 provided information about ground displacement in two main sectors; on the waste pile (maximum about $-486.5 \mathrm{~mm} /$ year) and on the pit benches (maximum about $-255.7 \mathrm{~mm} / \mathrm{year}$ ). For the waste dump, the detected deformation was related to settlements, showing values normally expected for this manmade structure, while for the cut slopes, lithostructural and lithogeomechanical attributes of the mine have played a key role in the control of the displacements. This research demonstrated that DInSAR analysis technique can be used for monitoring surface displacement in this kind of open pit mine located in a tropical rainforest environment (Amazon region), providing very useful information about the ground movement for alarm, planning and mining risk assessment.

\section{ACKNOWLEDGEMENTS}

This investigation was carried out under the scope of a FAPESP-Vale-INPE project (Process FAPESP \# 2010/51267-9). The National Council for Scientific and Technological Development $(\mathrm{CNPq})$ is also acknowledged for a grant received by the second author during the investigation. The authors would like to thank Vale S.A. for providing access to geological, geomechanical and in situ ground deformation data (SSR). Finally, the authors are particularly grateful to the Geotechnical Vale's team in Carajás for the support during the field work campaign.

\section{REFERENCES}

[1] Gabriel, A.K., Goldstein, R.M. and Zebker, H.A., "Mapping small elevation changes over large areas: Differential SAR interferometry" Journal of Geophysical Research 94, 9183-9191 (1989).

[2] Massonnet D., Rossi,D. M., Carmona , C. , Adragna, F., Peltzer,G., Feigl K., Rabaute ,T ., “The displacement field of the Landers earthquake mapped by radar interferometry" Nature, vol. 364, July, 138-142 (1993).

[3] Peltzer, G., Rosen,P. A., "Surface displacement of the 17 Eureka valley, California, earthquake observed by SAR interferometry" Science, vol. 268, June, 1333-1336 (1995).

[4] Massonet, D., Briole ,P., Arnaud, A., "Deflation of Mount Etna monitored by spaceborne radar interferometry" Nature, vol. 375, June, 567-570 (1995).

[5] Rosen, P., Werner, C., Fielding, E., Hensley, S., Buckley, S., Vincent, P., “A seismic creep along the San Andreas fault northwest of Park field, CA measured by radar interferometry" Geophysical Research Letters, 25 (6), 825-828 (1998).

[6] Strozzi, T., Wegmuller, U., Tosi, L., Bitelli, G., Spreckels, V., "Land Subsidence Monitoring with Differential SAR Interferometry" Photogrammetric Engineering \& remote Sensing, November, 1261-1270 ( 2001).

[7] Nagler, T., Rott, H., Kamelger, A., "Analysis of landslides in Alpine areas by means of SAR interferometry" Proc. IGARSS, vol. 1, Toronto, ON, Canada, July, 198-200 (2002).

[8] Lundgren, P., Usai, S., Sansosti, E., Lanari, R., Tesauro, M., Fornaro, G., Berardino, P., "Modeling surface deformation observed with SAR interferometry at Campi Flegrei caldera” Journal of Geophysics Research, vol. 106, September, 19355-19367 (2001).

[9] Usai, S, "A least-squares approach for long-term monitoring of deformations with differential SAR interferometry" Proc. IGARSS 2002, vol. 2, Toronto, ON, Canada, June, 1247-1250 (2002).

[10] Schmidt , D. A. Bürgmann , R., "Time-dependent land uplift and subsidence in the Santa Clara valley, California from a large InSAR data set” J. Geophys. Res., vol. 108, no. B9, September, 2416-2429 ( 2003 ).

[11] Mora, O., Mallorquí, J.J., Broquetas, A., "Linear and nonlinear terrain deformation maps from a reduced set of interferometric SAR images" IEEE Transactions on Geosciences and Remote Sensing, 41 (10), 2243-2253 (2003).

[12] Crosetto, M., Crippa, B., Biescas, E., "Early detection and in-depth analysis of deformation phenomena by radar interferometry" Engineering Geology, 79, 81-91 (2005). 
[13]Ng, A. H., Ge, L., Yan, Y., Li, X., Chang, H., Zhang, K., Rizos, C., "Mapping accumulated mine subsidence using small stack of SAR differential interferograms in the Southern coalfield of New South Wales, Australia" Engineering Geology 115, July, 1-15 (2010).

[14] Berardino, P., Fornaro, G., Lanari, R., Sansosti, E., “A new algorithm for surface deformation monitoring based on small baseline differential SAR interferograms" IEEE Trans. Geosci. Remote Sens., vol. 40, no. 11, November, 2375-2383 (2002).

[15] Lanari, R., Mora, O., Manunta, M., Mallorquí, J.J., Berardino, P., Sansosti, E., “A small-baseline approach for investigating deformations on full-resolution differential SAR interferograms" IEEE Transactions on Geosciences and Remote Sensing, 42 (7), 1377-1386 (2004).

[16]Lee, C., Lu, Z., Kwoun , O.,Won, H., "Deformation of the Augustine Volcano, Alaska, 1992-2005, measured by ERS and ENVISAT SAR interferometry" Earth Planets Space, 60, 447-452 (2008).

[17]Jiang, L., Lin. H., Ma, J., Yao, B. K., Wang, Y., "Potential of small-baseline SAR interferometry for monitoring land subsidence related to underground coal fires: Wuda (Northern China) case study" Remote Sensing of Environment 115, 257-268 (2011).

[18] Samsonov, S., D’Oreye , N., "Multidimensional time-series analysis of ground deformation from multiple InSAR data sets applied to Virunga Volcanic Province" Geophysical Journal International, 191, 1095-1108 (2012).

[19] Ferretti, A., Prati, C., Rocca, F.,"Nonlinear subsidence rate estimation using Permanent Scatterers in differential SAR interferometry" IEEE Trans. Geosci. Remote Sens. 38 (5), 2202-2212 (2000).

[20]Ferretti, A., Prati, C., Rocca, F., "Permanent scatterers in SAR interferometry" IEEE Transactions on Geoscience and Remote Sensing, 39 (1), 8-20 (2001).

[21] Werner, C., Wegmuller, U., Strozzi, T., Wiesmann, A., "Interferometric Point Target Analysis for Deformation Mapping" Proceedings of the IEEE International Geoscience and Remote Sensing Symposium (IGARSS 2003), Toulouse (France), vol. 7, 4362-4364 (2003).

[22] Hooper A, Zebker H, Segall P, Kampes B., "A new method for measuring deformation on volcanoes and other natural terrains using InSAR Persistent Scatterers" Geophysical Research Letters, 31, L23611, (2004).

[23] Paradella, W. R., Silva, M. F. F., Rosa, N. A., Kushigbor, C. A., "A geobotanical approach to the tropical rain forest environment of the Carajás Mineral Province (Amazon region, Brazil), based on digital TM-Landsat and DEM data" International Journal of Remote Sensing, 15 (8), 1633-1648 (1994).

[24] Daynes, W., “2013-Vale Brazil - Carajás Iron Ore Mine, Business Excellence, Simply ore Simply oreinspiring" < http://www.republicofmining.com/2013/01/31/vale-brazil-carajas-iron-ore-mine-by-will-daynesbusiness-excellence-january-30-2013> (01 July 2014).

[25] Vale S.A., "Geotechnical evaluation for the cracks area in the Raymundo Mascarenhas road and cut slopes of the N5W pit, N5W iron mine" Vale's internal report, 17 ps., original in Portuguese, (2012).

[26] Paradella W. R., Cheng, P., "Using GeoEye-1 Stereo Data in Mining Applications: Automatic DEM Generation", Geoinformatics, v. Jan-Feb, 10-12, (2013).

[27] Hopper, A., Bekaert, D., Spaans, K., Arikan, M., "Recent advances in SAR Interferometry time series analysis for measuring crustal deformation" Tectonophysics, 514-517 (2012).

[28] Golub, G., Loan, C., [Matrix Computations], John Hopkins University Press, Baltimore, 427-435 (1989).

[29] Werner, L. C., Wegmueller, U., Strozzi, T., "Deformation Time-series of the Lost-Hills Oil Field using a MultiBaseline Interferometric SAR Inversion Algorithm with Finite Difference Smoothing Constrains" AGU Fall Meeting, December, (2012).

[30] Goldstein, R.M., Werner, C.L., "Radar interferogram filtering for geophysical applications" Geophysical Research Letters 25 (21), 4035-4038 (1998).

[31] M. Constantini, “A Novel Phase-Unwrapping Algorithm based on Network Programming” IEEE Trans. Geosci. Remote Sens., vol. 36, no. 3, May, 813-820 (1998).

[32] BVP, "Lithostructural and lithogeomechanical mapping of the N5W mine" BVP internal report for Vale mining company, 61 ps, original in Portuguese, (2011). 